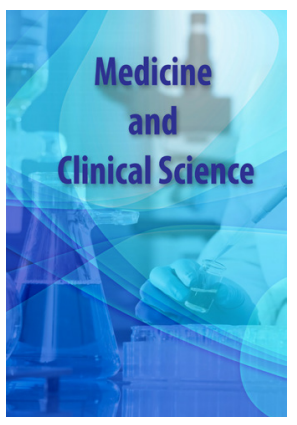

Correspondence

Javier Rodríguez Hernández

Director Médico Hospital La Fuenfría, Servicio Madrileño de Salud, Ctra. de las Dehesas, s/n, 28470 Cercedilla - Madrid, Spain

Tel: 91.852 .13 .57

E-mail: jrodriguezh@salud.madrid.org

- Received Date: 22 Nov 2019.

- Accepted Date: 03 Dec 2019;

- Publication Date: 11 Dec 2019.

Copyright

(c) 2019 Science Excel. This is an openaccess article distributed under the term of the Creative Commons Attribution 4.0 International license.

\title{
Root-Cause Approach to New Reality in a Mid- Long-Term Care Hospital in Madrid-Spain
}

\author{
Javier Rodriguez-Hernandez \\ Director Médico Hospital La Fuenfría, Servicio Madrileño de Salud, Ctra. de las Dehesas, s/n, 28470 Cercedilla - Madrid, Spain
}

\section{Introduction}

La Fuenfría Hospital (HLFF) is one of the three mid-long-term-stay hospital (MLTSH) facilities of the Madrilenian Public Health System of the Community of Madrid-Spain, (SERMAS). The HLFF, is located in the municipality of Cercedilla in the north of the Community of Madrid-Spain. Nowadays, we have at HLFF five clinical care units that are defined as: Chronic Care Unit, (CCU), Palliative Care Unit, (PCU), Tuberculosis Unit, (TBU), Functional Rehabilitation Unit (FRU) and the Neuro-Rehabilitation Treatment Unit (NTU). During the first half of 2016 there was another clinical care unit called of Unstable Chronic Care Unit (UCCU) that ceases to operate from May 2016, by incorporating the beds to this care unit to the CCU.

This lack of systematized processes has generated an undesirable effect on hospital management indicators. Apparently, the decision was based on the usual practice of processing applications at admission of cases. The selection at admission was based on empirical criteria of the cases before the centralization of the process in the Coordination Unit of Care Management (CUCM). This has been generating multiple inequalities and waiting lists that resulted in a clear impact on the care processes of the hospitals of origin. Since the second quarter of 2016, a centralized procedure for the referral of applications of admission to the MLTSH has been established, located in the SERMAS headquarter and specifically in CUCM with the full capacity of filtering the cases to admit at the HLFF.

Due to that, we consider that the Admision and Clinical Documentation Area (ACDA) within the areas of support available in HLFF and that the usual activity in this area was carried out without standardized operating procedures and appropriated documented or contrasted processes. It was necessary to consider the development of the areas of improvement and we consider the need to address the potential problems generated by centralization of admission. The main issue detected was a resistance to change and demotivation of the health care teams and support units. The latter aspect is related with the loss of ability to filter the admission requests as it was done prior to centralization.
Therefore, the reason that leads us to the development of this work, was to evaluate the impact of the establishment of a centralized process of referral of patients by the CUCM. This process of centralization has gone on to generate no impact on the profile of the patient's admission to the HLFF, due to the lack of internal processes of the ACDW for the processing of the admission request of patients. The incidence detected as more frequent among professionals of the HLFF, is the relative perception of the severity of the pathology presented by the patients who are admitted since the implementation of the centralization process. That perception was related to the fact that the CUCM lacks consistency with the some of the criteria for inclusion and exclusion of admission, available to the HLFF Clinical Units, with the exception of the PCU, which has a centralized process of admission since November 2013.

\section{Objectives}

Promote the normalization of processes in the Admission and Clinical Documentation Area (ACDA) follow the ISO 9001: 2015 NORM. Analyze the activities of the ACDA, describe the areas of improvement related to the centralization of the admission process of entry in the HLFF, on the activity of the ACDA. Design and document the processes of the ACDA before the centralization of the application process of entry into the HLFF. Establish indicators and control standards of the ACDA processes. Analyze the effect of the implementation of the processes in the ACDA, through hospital management indicator.

\section{Methods}

We performed a set of in-depth interviews and working groups in order to detect areas of improvement in ACDA activity with the different areas of interaction of the HLFF and especially with the different clinical care units, before the full implementation of the centralization model of the applications for admission to the MLTSH.

We proceeded to clarify the different processes in the activity of the ACDA, with the aim of detecting areas of improvement in process management, data management, and elimination of waste (which does not add value to a service) and determine the levels of organization, order and adherence to quality criteria of the ACDA processes.

An audit of the current ACDA processes of the HLFF was carried out to convenient document them. We 
met with all the members of the ACDA team in the process of auditing ACDA's activity. A total of 10 interviews / ad hoc work sessions were carried out with the members of the ACDA (7), the Assistance Units (17 [12 Area Specialists and 5 Nursing Supervisors]) and Support Units (1 neuro-psychologist, 1 clinical psychologist, 8 physical therapists, 2 occupational workers, 2 speech therapists, 3 radiology specialist technicians). The purpose of these sessions was to detect the areas of improvement and to adjust the inclusion and exclusion criteria of the patient admission care processes in the ACDA standards, consistent with the centralization of the application process.

Likewise, brainstorming sessions were held among the members of the ACDA, the Assistance Units and support areas, in order to detect areas of improvement in the performance of the usual activity of the ACDA.

We proceeded with the review of the basic processes for the inclusion of admission requests, the selection of admission care units, the registration of the clinical derivation documents, the reconciliation of medication upon admission (in case of admitting patients on drug treatment outside the HLFF pharmacy list).

Then we proceeded to the selection of the processes of the ACDA, in order to determine the most relevant and select among them those that need an additional analysis of potential areas of improvement that were detected.
The comparison technique was followed in pairs in order to prioritize the most recommendable areas of approach in order to carry out the re-engineering of processes susceptible to improvement.

We proceeded to analyze the priorities as double control with the analysis technique of Magnitude, Severity, Effectiveness and Feasibility, HANLO method

Flow diagrams of the main processes within the ACDA were designed in order to clarify the sub-processes that need to be optimized in order to incorporate them into the root-cause diagram. The root-cause diagram was used, in order to identify, explore and present in a graphic way with the maximum detail the processes with possible problems and try to determine the possible causes of these potential areas for improvement.

An action plan was proposed with the objective to produce a series of deliverables that range from defining an ad hoc description of the work position of the Area Specialist of the ACDA, following the proposals for defining the map of Competencies, Skills and Attitudes (CSA), until completing the standardized work processes currently available in the HLFF. Likewise, an ad hoc description of the job of the Administrative Assistant assigned to the ACDA must be included. Within the action plan, we focus on making the recommendations of the admission and discharge procedures in a standardized manner as suggested in the ISO 9001:2015 NORM.

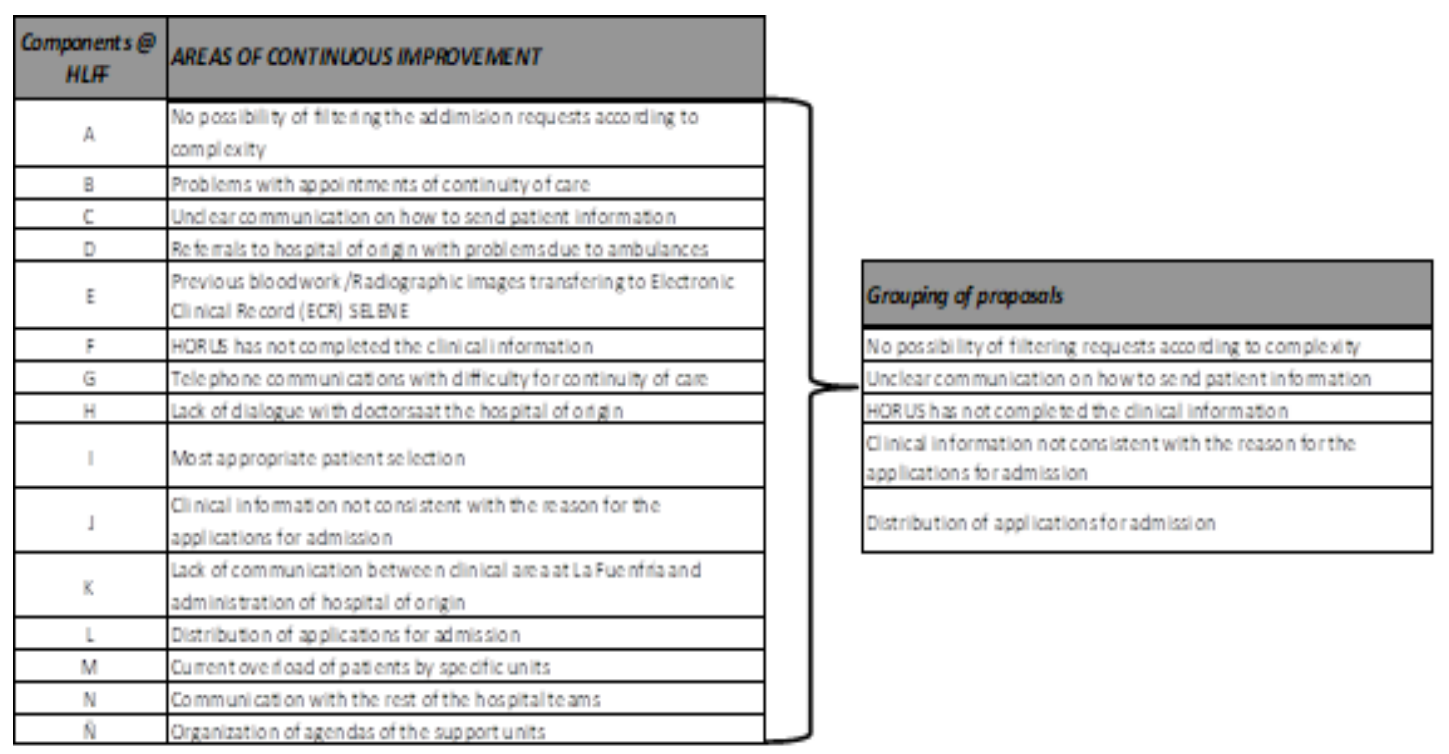

Table 1. Table of selection of areas for improvement of the HMLE entry processes centralized in the CUCM.

\section{Results}

ANALYSIS OF AREAS OF IMPROVEMENT OF THE PROCESS OF CENTRALIZATION OF APPLICATIONS FOR ENTRY.

As an outcome of the in-depth interviews and focus groups on the part of the evaluation of the impact of the centralization process for admission by the CUCM, to define the possible areas for improvement, we found what it is shown in table 1 .

It is appreciated that the most frequently mentioned as areas for improvement are selected and selected in the grouping of proposals, were the following:

- No possibility of filtering requests according to complexity / More appropriate patient selection

- Unclear communication on how to send patient information.

- Clinical general database has not completed the clinical information required.
- Clinical information not consistent with the reason for the applications for admission.

- Non-adequate admission request distribution.

PRIORITIZATION OF AREAS OF IMPROVEMENT OF THE PROCESS OF CENTRALIZATION OF APPLICATIONS FOR ENTRY

After carrying out this exercise, an in-depth analysis of the prioritization of the different proposed alternatives was carried out. The first exercise that was carried out was the prioritization in pairs of the previously grouped proposals, which are summarized in table 2 . It is derived from this that the aspects related to the lack of capacity to filter the entry requests according to criteria of complexity are the most relevant area. Later, as an additional validation, the Hanlo method was used to establish priorities based on the magnitude, severity, effectiveness of the possible solution and feasibility of the intervention and are summarized in Table 3. The ordered classification of the problems was obtained with the formula: Priority score: $(A+B) C x D$ 


\begin{tabular}{|c|c|c|c|c|c|c|}
\hline & & $a$ & $b$ & $c$ & $d$ & $e$ \\
\hline & & $\begin{array}{l}\text { No possibility of } \\
\text { Filtering requests } \\
\text { according to } \\
\text { complexity }\end{array}$ & $\begin{array}{l}\text { Unclear } \\
\text { cammunicatian an } \\
\text { haw to send patient } \\
\text { infarmation }\end{array}$ & $\begin{array}{l}\text { HORUS has not } \\
\text { completed the } \\
\text { dinical information }\end{array}$ & $\begin{array}{l}\text { Clinical infarmation not } \\
\text { carsistent with the } \\
\text { reasan for the } \\
\text { applications for } \\
\text { admission }\end{array}$ & $\begin{array}{l}\text { Distribution of } \\
\text { applicatiars far } \\
\text { admissian }\end{array}$ \\
\hline$e$ & $\begin{array}{l}\text { Distribution of } \\
\text { applications } \mathrm{f} x \\
\text { admission }\end{array}$ & $a$ & $b$ & $c$ & $d$ & \\
\hline$d$ & $\begin{array}{l}\text { Climical informatian } \\
\text { not consistent with the } \\
\text { reasan for the } \\
\text { applications for } \\
\text { admission }\end{array}$ & $d$ & $b$ & $d$ & & \\
\hline$c$ & $\begin{array}{l}\text { HORUS has not } \\
\text { campleted the clinical } \\
\text { information }\end{array}$ & $a$ & $b$ & & & \\
\hline$b$ & $\begin{array}{l}\text { Undear } \\
\text { cammunicatian an } \\
\text { how to send patient } \\
\text { information }\end{array}$ & $a$ & & & & \\
\hline$a$ & $\begin{array}{l}\text { No possibility of } \\
\text { filtering requests } \\
\text { according to } \\
\text { camplexity }\end{array}$ & & & & & \\
\hline
\end{tabular}

Table 2. Table of prioritization by pairs of the proposed improvement areas detected in the HLFF after the implementation of the centralization of applications for revenue by the CUCM.

\begin{tabular}{|c|c|c|c|c|c|}
\hline & $\begin{array}{l}\text { No possibility of } \\
\text { filtering requests } \\
\text { according to } \\
\text { complexity }\end{array}$ & $\begin{array}{l}\text { Unclear } \\
\text { communication on } \\
\text { how to send patient } \\
\text { information }\end{array}$ & $\begin{array}{l}\text { HORUS no tiene } \\
\text { completada la } \\
\text { informacion clinica }\end{array}$ & $\begin{array}{l}\text { Clinical information } \\
\text { not consistent with } \\
\text { the reas on for the } \\
\text { applications for } \\
\text { admission }\end{array}$ & $\begin{array}{l}\text { Distribution of } \\
\text { applications for } \\
\text { admission }\end{array}$ \\
\hline MAGNITUDE & 9 & 5 & 6 & 6 & 7 \\
\hline SEVERITY & 2 & 4 & 5 & 2 & 3 \\
\hline $\begin{array}{l}\text { SOLUTION } \\
\text { EFFECTIVENESS }\end{array}$ & 1,5 & 1,5 & 0,5 & 1,5 & 1 \\
\hline $\begin{array}{l}\text { INTERVENTION } \\
\text { FEASIBILITY }\end{array}$ & 1 & 1 & 1 & 1 & 1 \\
\hline TOTAL & 16,5 & 13,5 & 12,5 & 12 & 10 \\
\hline PRIORITY ORDER & $1^{x}$ & $2^{n d}$ & $3^{n}$ & 42 & 52 \\
\hline
\end{tabular}

\begin{tabular}{|c||c|c|}
\hline MAGNITUDE & $\begin{array}{c}\text { Number of people } \\
\text { affected }\end{array}$ & $0-10$ \\
\hline SEVERITY & Morbi-Mortality & $0-10$ \\
\hline $\begin{array}{c}\text { SOLUTION } \\
\text { EFFECTIVENESS }\end{array}$ & Easy or Difficult & $0,5-1,5$ \\
\hline $\begin{array}{c}\text { INTERVENTION } \\
\text { FEASIBILTY }\end{array}$ & $\begin{array}{c}\text { Relevance, } \\
\text { economy, resoures }\end{array}$ & 001 \\
\hline
\end{tabular}

Table 3. Summary table of prioritization according to the Hanlo technique of the proposed improvement areas detected in the HLFF after the implementation of the centralization of admission requests by the CUCM. 


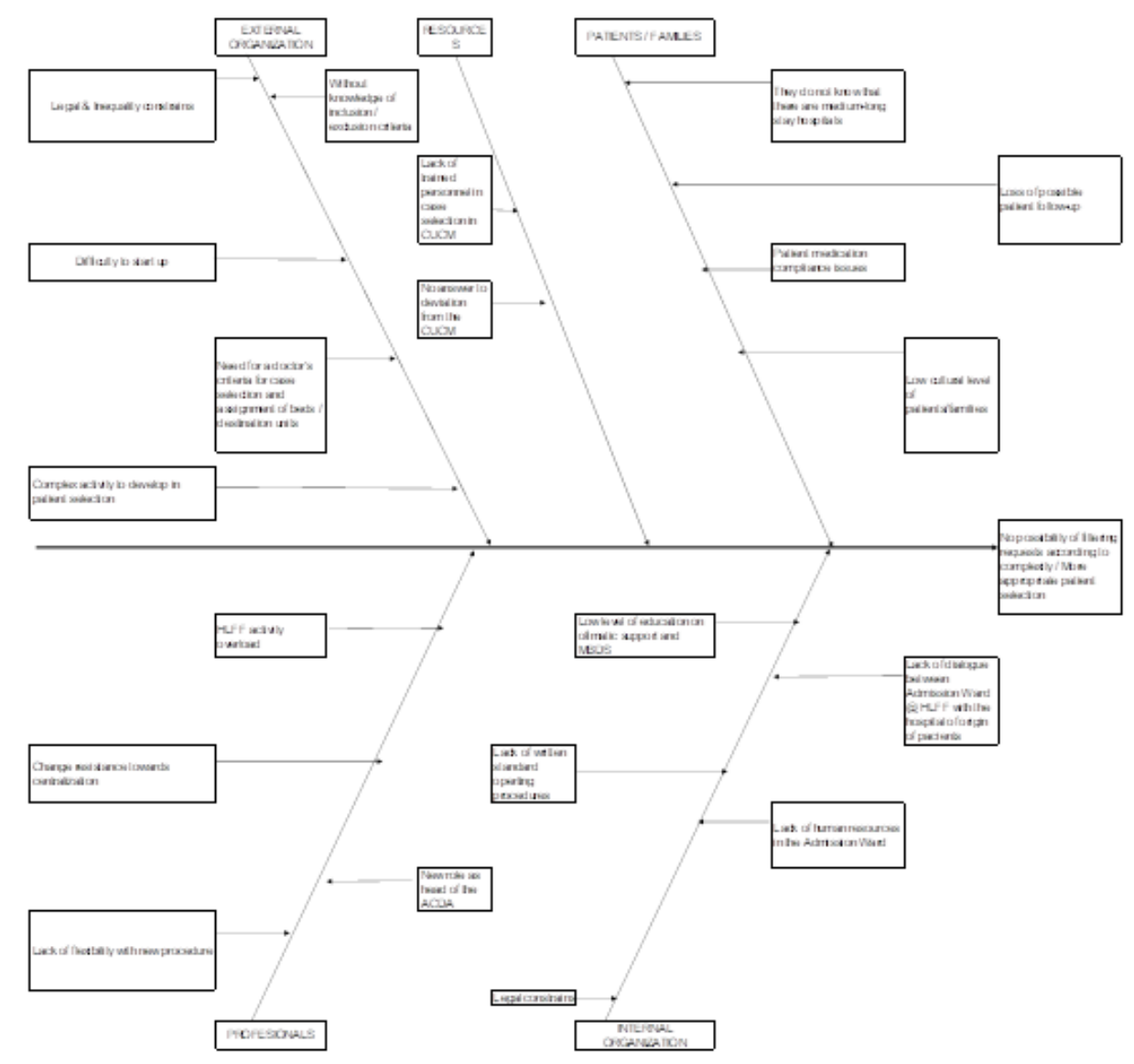

Figure 1. Root-cause diagram of the possible causal relationships of the lack of possibility of filtering entry requests in the HLFF according to complexity.

REVISION OF THE CAUSE-EFFECT OF THE IMPACT OF THE IMPLEMENTATION OF THE PROCESS OF CENTRALIZATION OF APPLICATIONS FOR ENTRY

With the result of the prioritization exercise, we have reviewed the possible causal relationships of the problems raised during the improvement area detection exercises, through the application of a root-cause diagram or causal diagram. The objective of making this graphical representation was to review the possible multiple cause-effect relationships between the possible / probable and diverse variables that intervene in a process that has been detected as an area of improvement, such as the lack of possibility to make filtering of requests according to complexity / selection of patients more appropriate. The Ishikawa diagram is presented in figure 1 .

The Ishikawa diagram has been ordered in the following dimensions:

- External organization

- Resources

- Users / relatives

- Professionals

- Internal organization

Each dimension was assigned a number of possible / probable causes, which were considered related to the detected problem.
ESTABLISHMENT OF WEIGHTING PROBLEMS RELATED TO THE IMPACT OF THE IMPLEMENTATION OF THE PROCESS OF CENTRALIZATION OF APPLICATIONS FOR ENTRY.

From the result of the analysis of the cause-effect relationship following the Ishikawa diagram, a series of problems were detected, evaluating them within a weighting table with the proposals of possible solutions, giving the same weight according to the following dimensions:

- Effectiveness

- Efficiency

- Feasibility

- Acceptance.

The result of the exercise of the weighting table, which is shown in table 4. Following the weighting exercise presented in Table 4, the possible solutions were assigned, and an execution date was assigned for the possible implementation of said solutions.

QUANTITATIVE ANALYSIS OF HOSPITAL MANAGEMENT INDICATORS OF THE IMPACT OF THE IMPLEMENTATION OF THE PROCESS OF CENTRALIZATION OF APPLICATIONS FOR ENTRY

Regarding hospital management indicators such as total discharge, average lengths and occupation percentages, the results of the effect of the implementation of admission centralization can be verified. The evolution shown in said indicators distributed by Clinical Units is discussed below (see in Figure 2) 


\begin{tabular}{|c|c|c|c|c|c|c|}
\hline Coure & Possible solution & Eftectheness & Etficlency & Foos bulluty & Acceptance & Total \\
\hline Legal B incqualty conctiona & 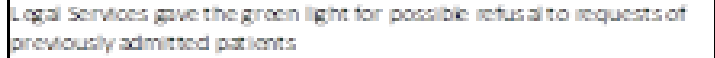 & 4 & 4 & 4 & 3 & 15 \\
\hline pithouly to start up & 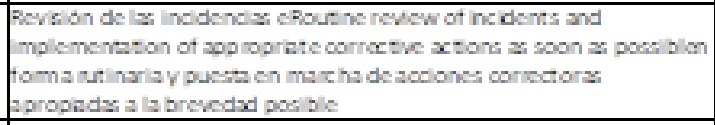 & 4 & 4 & 4 & 4 & 16 \\
\hline 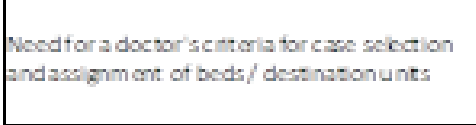 & 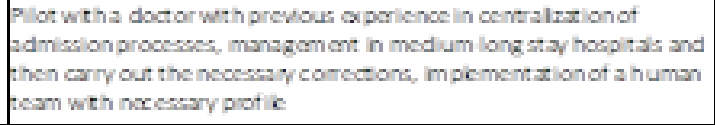 & 4 & 3 & 4 & 2 & 13 \\
\hline Complex sctuty to deveiop in paticnt selection & 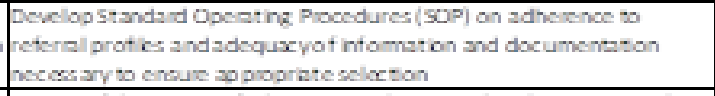 & 4 & 4 & 4 & 4 & 16 \\
\hline $\begin{array}{l}\text { Without knowicdge of indiution / ordution } \\
\text { emarb }\end{array}$ & 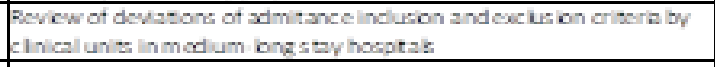 & 4 & 3 & 4 & 3 & 14 \\
\hline No ank wer to devasion from the CuCM & 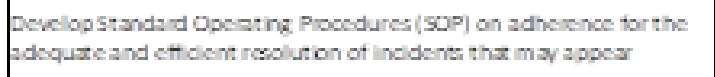 & 4 & 4 & 4 & 4 & 16 \\
\hline $\begin{array}{l}\text { Lack of traned personnel lincase secetion in } \\
\text { CucM }\end{array}$ & 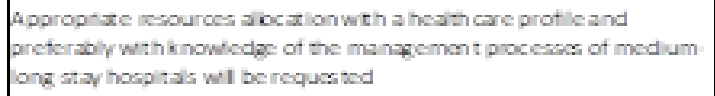 & 4 & 4 & 4 & 2 & 14 \\
\hline $\begin{array}{l}\text { They do not know that thereare medium long } \\
\text { tay hospts's }\end{array}$ & $\begin{array}{l}\text { Developa communication plan for acute hos pts's on medium bong } \\
\text { ftay hosptak and develop reception materkil to be delveredto } \\
\text { patentsand tamily members/ companions }\end{array}$ & 4 & 4 & 4 & 4 & 16 \\
\hline fort of pocalbe psiont follow up & 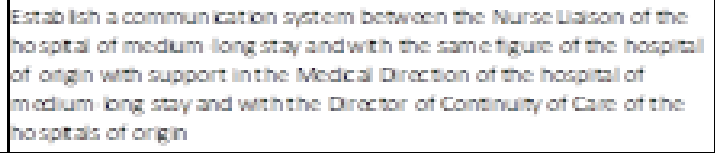 & 4 & 4 & 4 & 4 & 16 \\
\hline Pasent medicason complance ksucs & 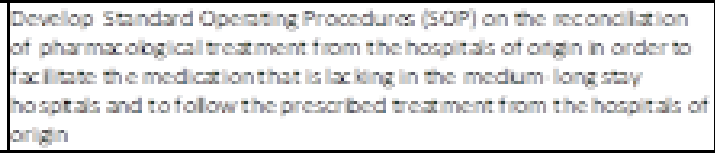 & 4 & 4 & 4 & 3 & 15 \\
\hline Low cuturs kvel of pationts/tamilics & 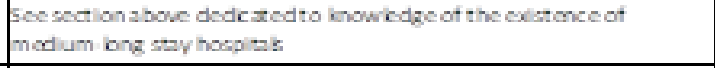 & $\mathrm{N} / \mathrm{A}$ & N/A & $N / A$ & $N / A$ & N/A \\
\hline HLF sevtyouctosd & 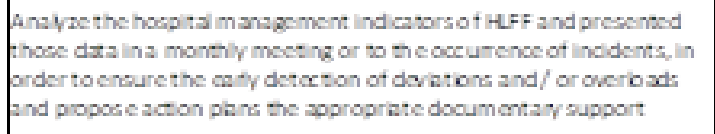 & 4 & 4 & 4 & 3 & 15 \\
\hline Change resictancetowardz centalzason & 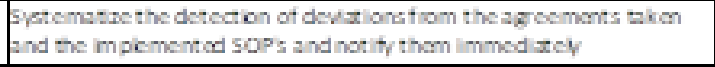 & 4 & 4 & 4 & 3 & 15 \\
\hline New roie $2 \mathrm{~s}$ hed of the $A C D A$ & 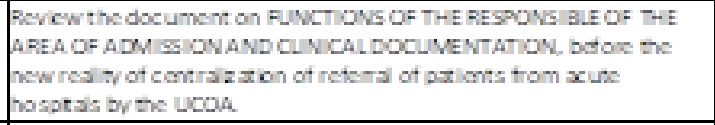 & 4 & 4 & 4 & 3 & 15 \\
\hline Lack of texib ty weth new procedure & 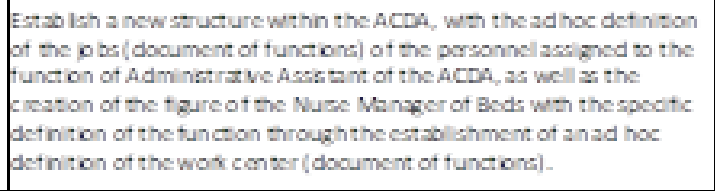 & 4 & 4 & 4 & 3 & 15 \\
\hline Legal contant int & 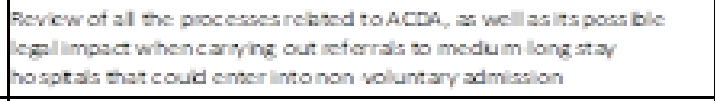 & 4 & 4 & 4 & 3 & 15 \\
\hline -ack of witten standard operting procedures & 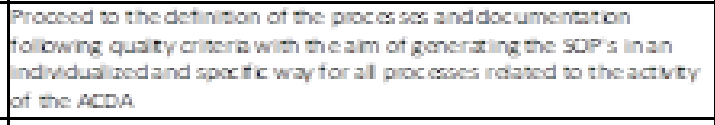 & 4 & 4 & 4 & 3 & 15 \\
\hline $\begin{array}{l}\text { Low level of educzion on ot msric support and } \\
\text { MBDS }\end{array}$ & $\begin{array}{l}\text { Add oft mase taning on and ACDA in tems of datw acquatison, dra } \\
\text { management and dra anshels relsredto the ICD } 10\end{array}$ & 4 & 4 & 4 & 3 & 15 \\
\hline 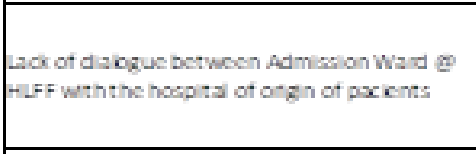 & 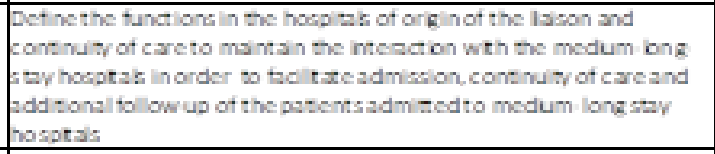 & 4 & 4 & 4 & 3 & 15 \\
\hline $\begin{array}{l}\text {-ack of hum an nesources inthe Admiacion } \\
\text { Ward }\end{array}$ & 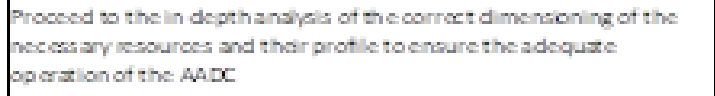 & 4 & 4 & 4 & 3 & 15 \\
\hline
\end{tabular}

Table 4. Weighting table of solutions proposals to the problem of lack of possibility of filtering the requests to enter the HLFF. 


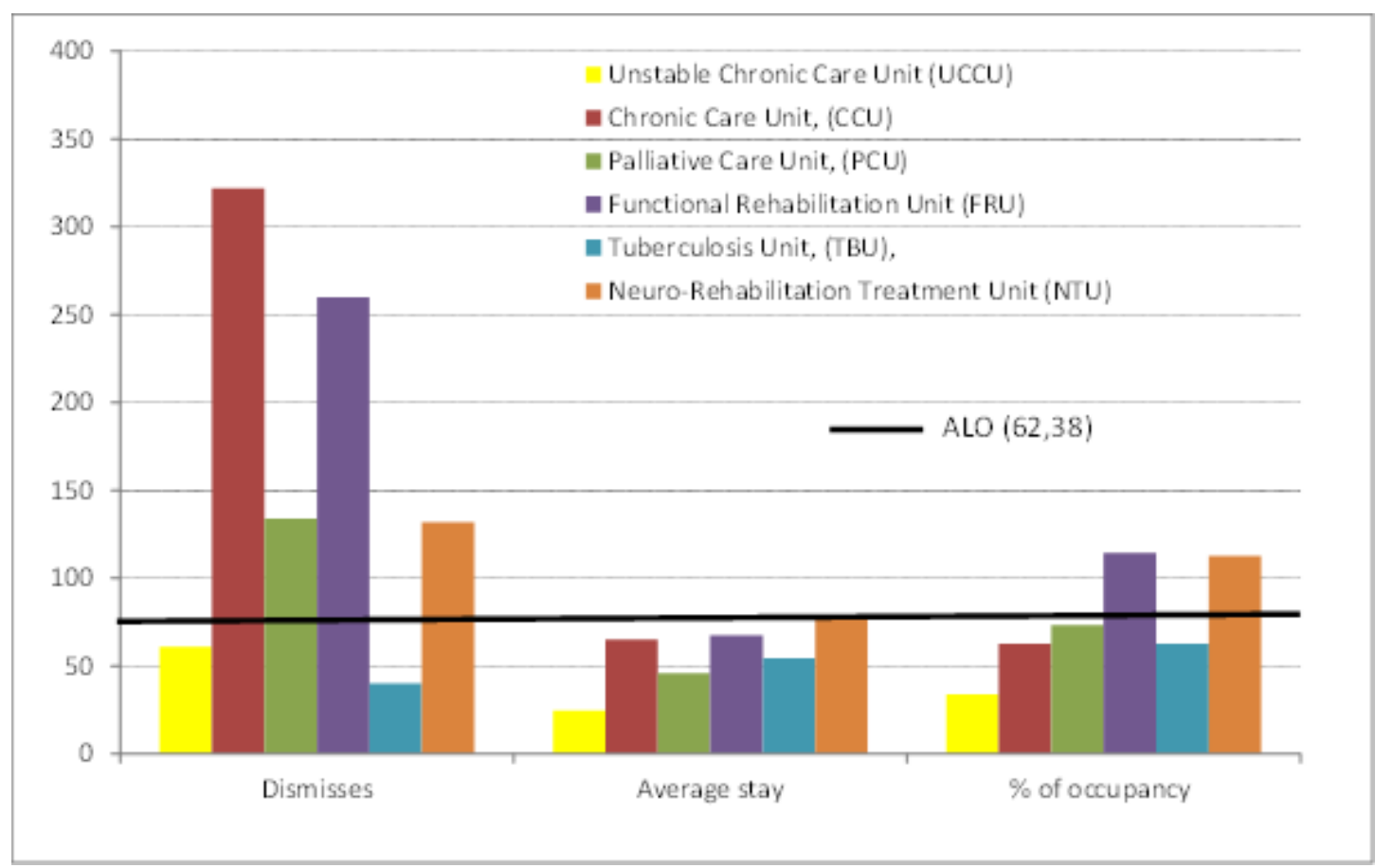

Figure 2. Comparison of total dismisses, average stay and \% of occupancy per Care Unit during 2016. (SOURCE SELENE)

In the data of hospital management indicators at the end of 2016 represented in figure 2 allow to infer a change in terms of the number of discharges of patients who have been discharged from the UCCU, who have been reduced in absolute number of discharges, becoming the second health unit with the lowest number of discharges during 2016. The average length of stay (ALOS) of 2016 was 62,38.

The centralization of the requests of admission towards the MLTSH generates a change in the perception of the different functional areas of the hospital on the profile of the admitted patients. A current of opinion was detected among the professionals of the clinical units and of the support areas, based fundamentally on perceptions about the degree of complexity of the patients. This profile perception of more complex patients is mainly related to the cessation of UCCU activity. This is temporarily associated with the loss of the filtering capacity of the applications for admission by the ACDA of the HLFF, which depends on the direct from the CUCM, since May 2016. With the centralization in hypothesis, the management problems that apparently were generated previously in the ACDA. The adherence to the inclusion and exclusion criteria of the admission to the HLFF, was transferred to the CUCM and the perception of the professionals of the HLFF, is that this adherence to the inclusion and exclusion criteria guidelines is not correct.

For the analysis of the impact of the centralization of the income requests in the CUCM, in terms of the complexity of the patients referred to the HLFF, we proceeded to compare the complexities based on the data of the Minimum Basic Data Set (MBDS) available. The measure of complexity was made based on the weights of each Diagnosis-Related Group (DRG) of the patients who were discharged from the HLFF. It is defined that associated with a specific Patient Classification System (PCS), the Average Weight (AW) is a synthetic descriptive measure of the complexity load attended by a healthcare service provider. For the case of hospitalization, for example, the AW of a hospital informs us of the complexity treated by a hospital facility. We have followed the definition of AW as the arithmetic mean of the Relative Weight (RW) of all the episodes of hospitalization, once classified in Diagnosis Related Group (DRG), based on the iso-consumption properties of each one of the diagnoses.
The AW is an indicator of the expected consumption of an episode of care (or a series of episodes) with respect to the expected consumption of a baseline episode taken as a reference. In its most disaggregated aspect, the Relative Weight of an episode grouped in a DRG represents a measure of the expected cost of that episode with respect to the average episode. The objective has been to know to what extent it is more or less complex (in terms of expected cost) the activity carried out by a hospital with respect to similar hospitals (for example, to analyze the expected costs of said hospital with respect to what would be expected).

Likewise, through the information provided by the RP of the DRGs, it is possible to analyze whether in a hospital and / or service and / or unit a more or less complex clinical case attended to in a given period than in the same hospital and / or service and / or unit in another timeframe.

As mentioned, very convincing case reports may allow conclusions that mifepristone can, in some instances, provide an extended improved quality of life in patients with advanced and metastatic non-small cell lung cancer. Though mifepristone did not show benefit for unresectable meningiomas (possibly these become tumors are too slow growing), the large number of cases of meningiomas treated with mifepristone, clearly demonstrated that daily mifepristone is extremely well tolerated with no significant health risks [22]. We eagerly await the conclusion of the 40 patient study to determine what percentage of patients with stage IIIB or IV non-small cell lung cancer, now recalcitrant to standard therapy, may receive palliative benefits from single agent oral mifepristone therapy.

In Figure 3, you can see the evolution of the average weight of the DRG's of patients discharged data during 2016 from HLFF. The dotted line is the trend of the average weights during the indicated period. There is no apparent seasonality in the distribution of AW over the period analyzed and shown in the graph, in a full year we see an apparent increase in the complexity of patients discharged from the HLFF, basing said affirmation of the increase in the weight of DRGs throughout the time analyzed. 


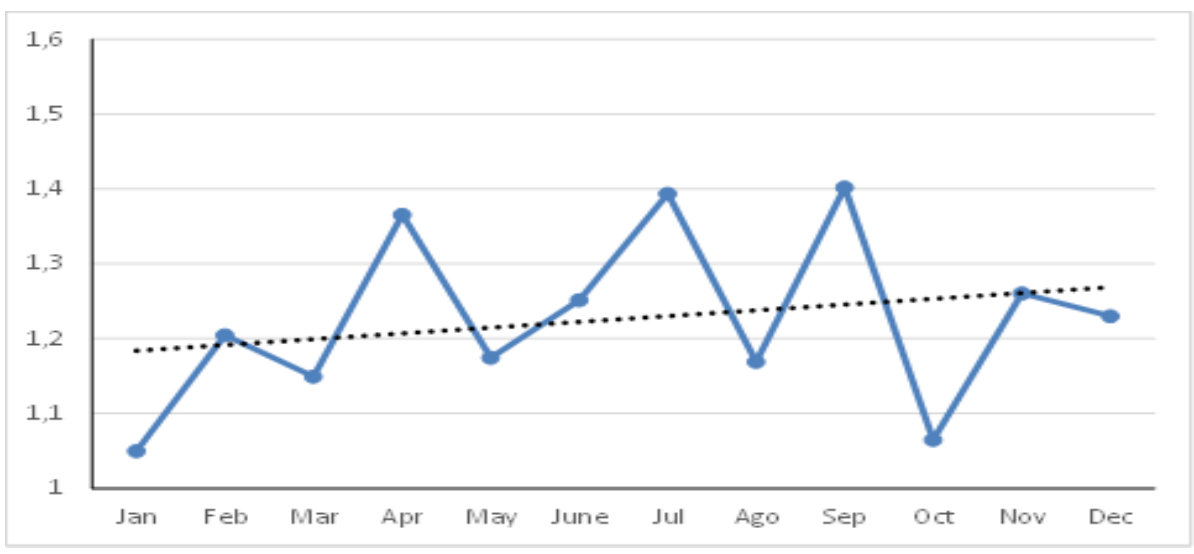

Figure 3. Evolution of the AW of the DRG's of patients of HLFF discharged patients during 2016. The dotted line shows the trend line of the average weights during the indicated period (SOURCE MBDS analytical tool of iAmetrics)

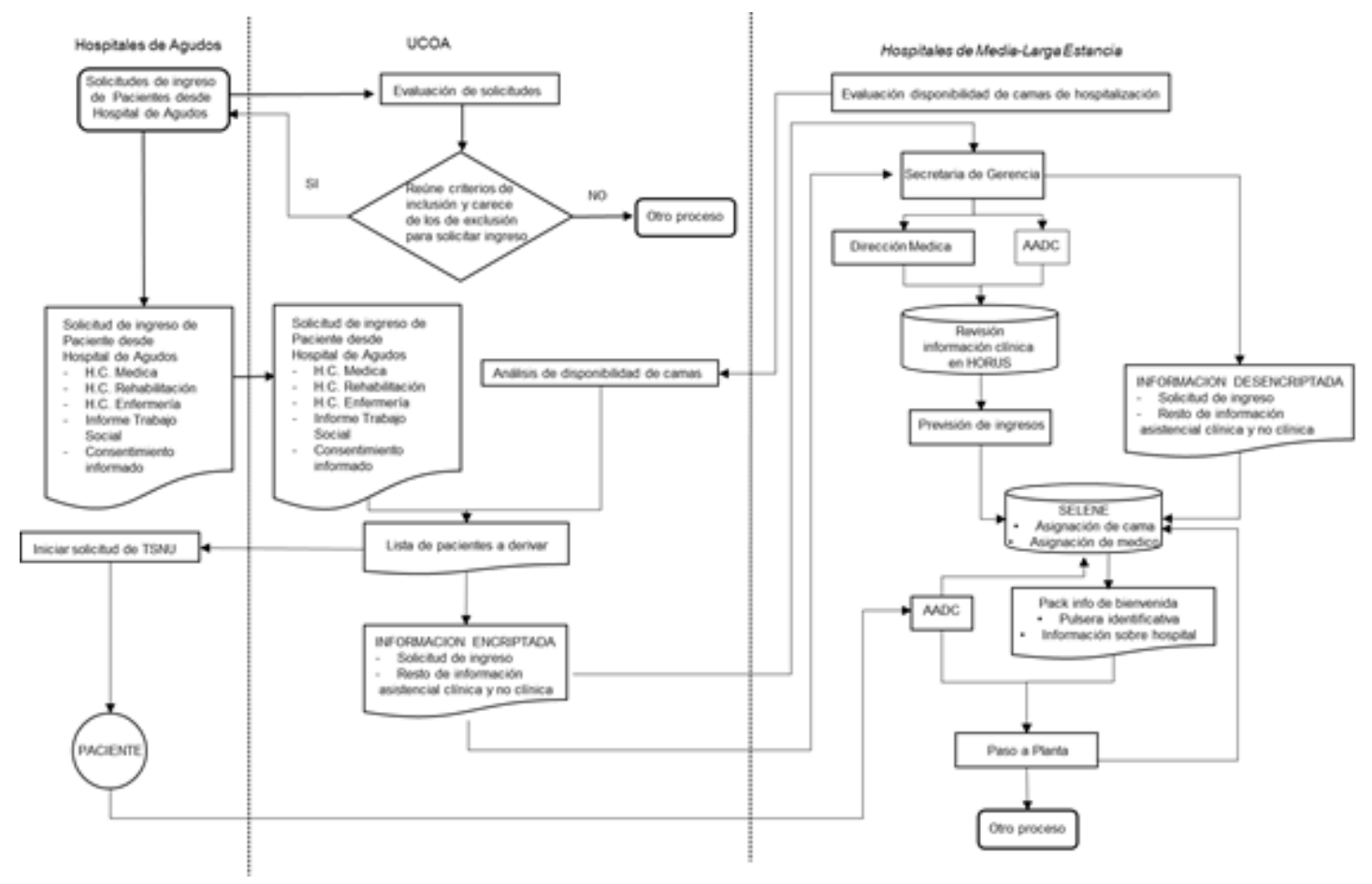

Figure 4. Flow diagram of the HLFF application process from the centralization of admission requests.

It was recommended to initiate an improvement plan oriented according to the analysis expressed in the improvement areas detected. To this end, a process of assigning responsible persons to the proposed solutions was initiated and performed during the second half of 2016, a detailed mapping of specific processes of the ACDA, a preparation of the flowchart was carried out that would lead to the proper articulation of the centralization process of the applications for admission to the HLFF. The fundamental objective has been to articulate and harmonize the flow of information that allows an appropriate planning of the information of the number of beds available in the HLFF, by clinical units. With this in the CUCM, after analyzing the potential demand for HMLE beds, it would facilitate the provision of transfers to centers such as the HLFF and thereby plan the allocation of support resources for clinical units.

Figure 4 shows the flow diagram that has been proposed and implemented according to the CUCM as an approach to the flow of information required for the centralization of the application process. The proposal of this process and its follow-up has been established internally in the HLFF, in order to detect the adequacy of the same to the internal processes of admission of patients in the hospital and the adjustment to inclusion and exclusion criteria that are available. .

Within the process of implementing the improvement proposals, we proceeded to:

- Communicate to the CUCM the deviations of the established process,

- Monitoring of hospital management indicators is maintained and

- An analysis of the complexity indicators within the CMBD of the GRS's of patients who have been discharged has been carried out, within the monitoring of the process. 


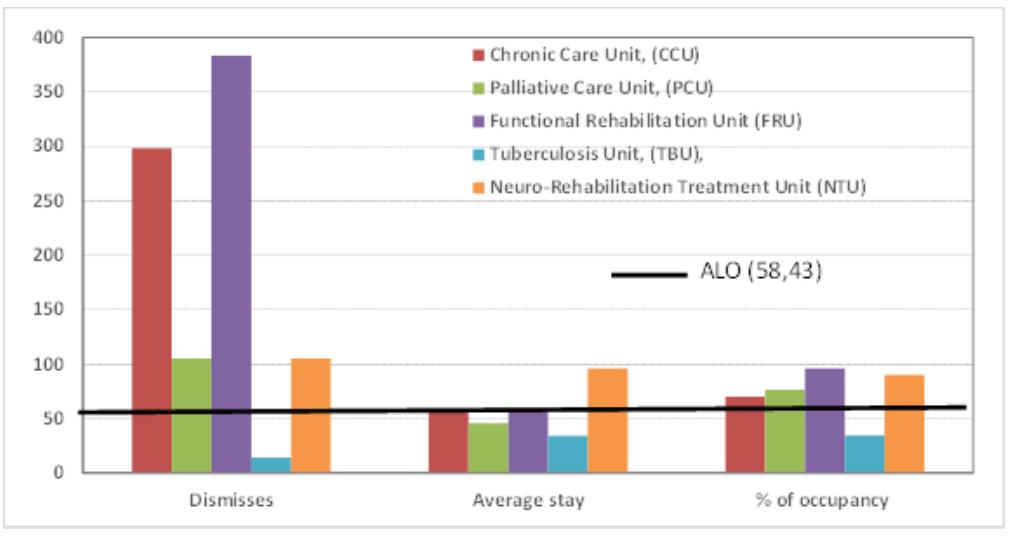

Figure5. Comparison of total dismisses, average stay and \% of occupancy per Care Unit during 2017. (SOURCE SELENE)

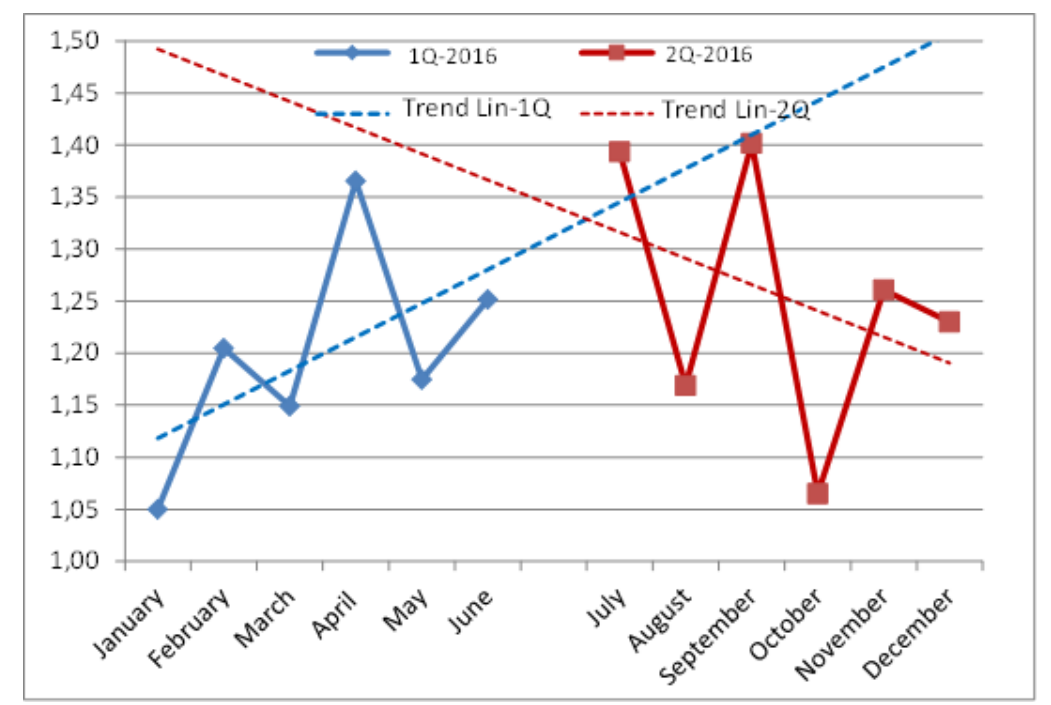

Figure6. Monthly evolution of the WA of the DRGs, with separation by semesters of 2016 of patients discharged from the HLFF in 2016'. (SOURCE MBDS analytical tool of iAmetrics)

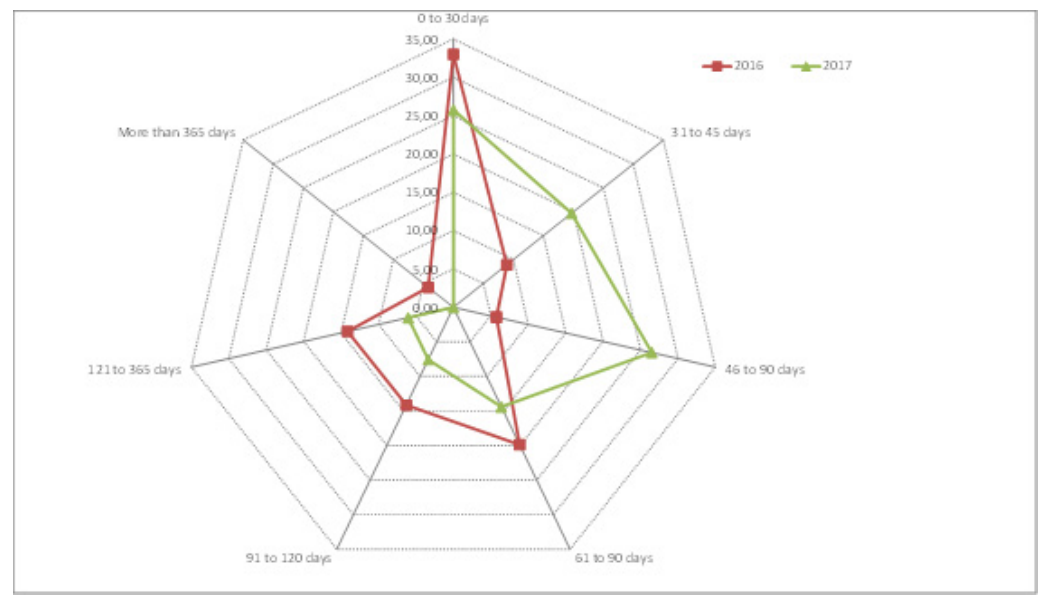

Figure7. Comparative temporal evolution of the percentages of patients grouped by intervals of stays in the HLFF during 2016 and 2017. (SOURCE SELENE) 
The hospital management indicators at the end of 2017 represented in figure 5 shows a change in terms of the number of discharges of patients by clinical units. The main change is related with the total number of patients dismissed from FRU and the reduction to zero of the activity of the UCCU. The ALOS in 2017 was reduced to 58.43 compared with 2016

If we graph (see figure 6) separately the first and second semesters of 2016, we can see that the supposed effect of the increased complexity since the implementation of the centralization of the applications for admission to the CUCM does not seem to be such. Moreover, in the second half of 2016, when expressing it in trend lines, it can be seen that the trend is rather on the contrary it is decreasing.

These results can therefore explain the slight tendency towards improvement in terms of hospital management indicators, mainly in terms of ALOS that has been detected in 2016

In Figure 7, it can be seen that the percentage of patients with stays exceeding 90 days (between 91 and 210 days) was close to $20 \%$ of the patients admitted during 2016. This has an impact on the indicators of hospital stay and the activity of the hospital plus a deviation to a long stay that half a stay. Likewise, it is shown that the polygon that represents the average stays by ranges during 2016 presents a different form with more load over extended ranges of stays. This could be because the lengths of stay of admitted patients is possibly affected by carry-over effect of the pre-centralization of admission requests process period. In fact, the shape of the polygon of the 2016 data is similar to de 2015 (data no shown). The 2017 data indicate a different shape according with maintenance of the improvement process implemented.

Regarding the 2017 AW data also indicate an improvement in terms of decrease of weigh (data no shown) and coincident with the decrease ALOS (Figure 6)

\section{Discussion}

The present work has been proposed as a need to adapt the activity of the AADC of the HLFF to an organizational change that generates the centralization in the UCOA, of the management of the requests of patients in the HMLE. These processes for the management of patient admission requests, likewise, have repercussions in relation to the care activity and support activities, being the same as possible to quantify in the hospital management indicators. This change we consider that therefore requires a rigorous approach.

We have proceeded to review the management processes of patient income requests in the HLFF, as a result of the implementation of a centralization of income requests in the UCOA and the impact that this change has had on the activities of the HLFF.

The first review of the processes was carried out in the AADC, adding to the daily activities the issuance of a list of availability of beds in the hospital for the UCOA. This activity generated resistances in the HLFF as it was perceived as a loss of autonomy from the usual hospital management. The implementation of a coordination of the usual activities of the AADC with the UCOA and the transfer to the latter of the filter capacity of the patients' income generated internal resistances that were transmitted to the rest of the functional and support areas of the HLFF.

One of the operational changes carried out in the HLFF was the extinction of activities of the UCA. This unit involved the elimination of acute patient referrals from chronic processes, which could usually lead to the occupation of beds in acute care hospitals, with potentially higher than average stays, and in the case of HLFF, stays shorter than the average. half. These patients in some cases were considered subsidiary of home follow-up that did not occur due to the resistance of the relatives and / or the patients themselves to follow treatments with the assistance support of the Primary Care.

Another change that arose with the new process of managing applications for admission to the UCOA was the centralization of the referrals of all the patients of the PCU to the PAL24 service. This service has a long experience in centralization of referral requests in order to respond quickly to the demands of income from any point of the health system, both from the level of Primary Care supported by the ESAD activity, as well as from their own Services of Hospitable Units of Palliative Care.

Therefore, in the new activity scenario, all requests for admission to the HMLE in central SERMAS services are centralized, in addition to those already available for palliative care subsidiary patients through PAL24.

To the beds availability of the HMLE beds were added, for the same profile of patients, in hospitals of intermediate size with previous experience of intermediate care. This has been the case of adding to the hospitals of the Red Cross, Virgen de la Torre, Santa Cristina, groups of beds to give support similar to the HMLE, The final goal has been to add availability of beds of medium-long stay in these hospitals, respond to the incremental demand for such beds in the SERMAS. This has been intended to reduce or eliminate occupation of beds in acute care hospitals with higher costs per stay and with a potential impact on the generation of surgical waiting lists and diagnoses at that level of care.

To address the areas of improvement detected in the HLFF given the new process for managing income requests, a series of in-depth interviews was conducted in the affected units and work sessions in the functional areas in order to clarify the possible improvement actions. As a result of them they focused on the following areas:

1. No possibility of filtering requests according to complexity / Selection of patients more appropriate,

2. Unclear communications on how to send patient information.

3. HORUS has not completed the clinical information.

4. Clinical information not consistent with the reason for the applications for admission and

\section{Cases admission distribution.}

The results of the areas of improvement detected were applied to techniques of prioritization by pairs and the HANLO method, determining that the one that required a selective approach was the one referring to the possibility of filtering requests according to complexity / Selection of patients more appropriate

By applying the method described as cause-effect by Ishikawa, various activities that required a specific approach were determined, it is aspects related to the dimensions of: 1.- External organization, 2.- Resources, 3.- Users / relatives , 4.- Professionals and 5.- Internal organization. From this exercise we proceeded to detect sub-causes related to the dimensions described above.

Likewise, the analysis of each of the sub-causes was considered weighting of proposals for solutions to the problem of lack of possibility of filtering the applications for admission to the HLFF. Said proposals for solutions were submitted to an analysis of effectiveness, efficiency, feasibility and feasibility, assigning the results of the analysis of said aspects as weight.

Subsequently, each sub-cause of each analyzed dimension was analyzed to make a possible solution proposal, assignment of a responsible person and date of execution of the solution proposal.

From the quantitative analysis carried out, we focused on hospital management indicators to verify the effect of the centralization of income management in the UCOA. In the comparison of the activity closings of 2016 compared to 2015, we detected a reduction of discharges from the UCA of $63 \%$, when the activity of said unit ended as of May 2016. However, in the global reduction of discharges A reduction of $6 \%$ is observed, mainly due to an increase in discharge from patients admitted to the UTN, which increased the number of discharges by slightly less than $61 \%$. The increase in activity of the UTN, has required a redistribution of the resources that were previously occupied with the UCA as soon as, passing them to give support in the UTN, to overcome the excess of activity derived from the greater complexity of the patients admitted in the UTN. Suffice it to indicate that they are patients whose diagnosis is fundamentally that of ischemic and hemorrhagic stroke, or else traumatic brain injuries resulting in additional hemorrhagic 
pathology.

Finally, in the quantitative analysis, it is worth mentioning the decrease in the number of patients admitted from the UTB, in line with the lower demand for tuberculosis income, in line with the epidemiological indicators of the disease.

Using the analysis of the GRD's weights of the discharges issued in 2015 and 2016, there is a tendency to increase the weights of the DRGs, with which we can infer that the complexity of the patients who registered since the HLFF, it has progressively increased.

With the results of the completed exercise, we proceeded to the additional analysis of the process maps of the HLFF. The main conclusion was the need to review the maps of processes and sub-processes of the AADC. All of this in front of the new reality of centralization of admission requests in the UCOA and adapting this to the specific needs of having in the staff a profile of skills, competences and attitudes different from the previously available with an AADC with activities of selection and denial of applications for admission.

Likewise, as part of the improvement process detected with respect to the need to have a map of skills, competencies and attitudes, a draft proposal was generated that fits the new reality of centralization of management processes. applications for admission to the HLFF, which is considered to be possible to be extrapolated and adjustable to other HMLE. The results of the implementation of a map of skills, competences and attitudes, it would be desirable to implement a validation and evaluation process that will be integrated into the process of assessment of the performance of the AADC responsible and the detection of the training and development needs of the responsible position.

The improvement plan was put in place since the areas for improvement were defined. The process maps of the HLFF were reviewed and a definition of the specific AADC process was carried out, generating a flow chart with the objective of standardizing the processes and subprocesses within defined in AADC. In the new situation of centralization of management of admissions requests to the HMLE. The new process involved coordinating the activities regarding the analysis of bed availability in the HLFF and proceeding to communicate it to the UCOA in the early morning. From this proceeding from the implementation of the process to selection of entry requests issued from the acute care hospitals of the Community of Madrid and to distribute them to the HMLE according to the availability of these in terms of beds by clinical units. The clinical documentation together with the approvals for the applications for admission and for the sanitary transport is issued from the UCOA, so that the issuing hospitals begin the processing for the next day's transfers.

The clinical, nursing care and social workers information is transmitted in an encrypted format from the UCOA to the HMLE and is made available here for the care units. All the information step is done in support in the SELENE electronic clinical record system. The information referring to the stay and discharge of patients is passed from SELENE to CMBD analysis environments, after coding. The analysis of the codes is determined by the available information on the complexity of each of the DRGs, and this allows comparisons to be made of follow-up in periods determined by the time required.

We proceeded to the analysis of the complexity of the DRGs of the 2016 registrations, as well as the analysis of the weights of the mentioned DRGs. We detected that it was not possible to demonstrate the information referred to the increase in complexity related to the centralization of the management of the applications for admission. In the HLFF, the analysis of the hospital management indicators it was possible to conclude that the patients had ALO shorter than the period prior to the implementation of the centralization of income management.

\section{Summary}

From the present work we can conclude the aspects that we will enumerate next:

\# 1.- The centralization of the process of managing applications for admission to the HMLE has not had any impact on the increase in the complexity of patients treated in the HLFF.

\# 2.- It is necessary to have an ad-hoc analysis of the processes that the HMLE have, with the objective of identifying areas of improvement that allow taking corrective actions of said processes when they consume resources unnecessarily and / or do not add value to the care processes.

\# 3 .- Validation of the map of competences of the head of the AADC of the HMLE is required in order to adapt the performance to the new reality of centralization of the process of management of the applications for admission.

\# 4 .- Carrying out the sizing of care needs in terms of care to admitted patients allows, in addition to monitoring deviations and detect unused capacity of resources, potentially useful in other areas, being clearly the Social Work the most relevant to take into account.

\# 5.- The exercise of analysis of the area of improvement practiced in this work focused on the processes, results and proposing a structured approach to these processes has allowed to propose the bases for a systematized sizing of resources. This has allowed us to have the flexibility to use previously used capacity for the UCA and through the redistribution of resources, to move to clinical units with greater needs of nursing resources, nursing assistants and caretakers, UTN, thereby improving the results of hospital management indicators.

\# 6.- The recommendations of review of the processes and re-location of the resources were decided initially, before the supposed increase of the complexity that indicated the assistance areas of the HLFF.

\# 7.- It is necessary to establish as an objective of the redistribution of resources and the flexibility of assignments, to be able to dispose of said resources in areas with greater potential assistance burden. This must be accompanied by the availability of a precise analysis of the results in terms of hospital management indicators and a reliable analysis of the MBDS.

\section{Acknowledgements}

I am grateful to wife Marisa Vaello, MSc, $\mathrm{PhD}$ for her partner and support. Also to Dolors Montserrat MD PhD, who has so kindly given guide with the tools of quality. To Manuel de la Puente MD, Managing Director of La Fuenfría Hospital. Also Juan del Llano, for his technical advice and finally in memoriam to Joaquim Camprubí, who has been supporting my requests for guidance on WhatsApp

\section{References}

1. Ramos Martin-Vegue, A.J. Papeles Médicos 2000, 9 (1): 32 - 38

2. BOE REAL DECRETO 866/2001 (https://www.boe.es/diario_boe/txt. php?id=BOE-A-2001-15347)

3. Sistemas de gestión de la calidad. Requisitos (ISO 9001:2015). UNE-EN ISO 9001.

4. https://www.medicare.gov/Pubs/pdf/11347.pdf

5. The memory jogger by Brassard M. and Ritter Diane, 1994 Edited by GOAL/QPC

6. Reengineering the corporation. A manifesto for business revolution by Hammer M. and Champy J., 1994. Edited by HarperCollins Publishers

7. Reengineering management. The mandate of new leadership,1995. Edited by HarperCollins Publishers

8. Committee of Experts on Management of Safety and Quality in Health Care (SP-SQS) Expert Group on Safe Medication Practices. http://www. bvs.org.ar/pdf/seguridadpaciente.pdf

9. Miquel Arjona Torres, Innovación en organización y gestión. Gestión Clínica. Vías de avance. 2014. Del Llano Señariz Juan Ernesto et al. Ediciones Pirámide.

10. Informe epidemiológico sobre la situación de la tuberculosis en España. Año 2014. En http://www.isciii.es/ISCIII/es/contenidos/fdservicios-cientifico-tecnicos/fd-vigilancias-alertas/fd-enfermedades/ pdf_2015/TB_Informe_2014.pdf

11. http://www.iasist.com/

12. http://www.sld.cu/galerias/pdf/sitios/infodir/guia_elaboracion_ mapas_competencias.pdf.http://www.iasist.com.es/es/046/IASIST 